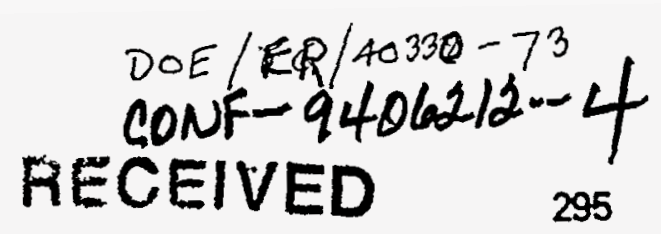

1. Phys.

\author{
JAN $O 41996$
}

\title{
OSTI
}

\section{SHAPE COEXISTENCE AND ELECTRIC MONOPOLE TRANSITIONS}

John L. Wood

School of Physics, Georgia Institute of Technology

Atlanta, Georgia 30332-0430, USA

(1974)

18.

is. Lett.

7.

\section{Abstract}

The evidence for a widespread association of electric monopole transitions with shape coexistence is reviewed.

\section{DISCLAIMER}

This report was prepared as an account of work sponsored by an agency of the United States Government. Neither the United States Government nor any agency thereof, nor any of their employees, makes any warranty, express or implied, or assumes any legal liability or responsibility for the accuracy, completeness, or usefulness of any information, apparatus, product, or process disclosed, or represents that its use would not infringe privately owned rights. Reference herein to any specific commercial product, process, or service by trade name, trademark, manuiacturer, or otherwise does not necessarily constitute or imply its endorsement, recommendation, or favoring by the United States Government or any agency thereof. The views and opinions of authors expressed herein do not necessarily state or reflect those of the United States Government or any agency thereof. 
$y=\ldots t: \ldots$

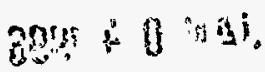

is
INTERNATIONAL CONFERENCE ON

NUCLEAR

$\mathbb{S H P P E}$

AND

NUCLEAR

STRU[TURE

AT LOW

EXCITATION

ENERGIES

ANTIBES (France) June $20-25,1994$

Edited by:

M. Vergnes - D. Goutte - P.H. Heenen - J. Sauvage

EDITIONS

FRONTIERES 


\section{Introduction}

Shape coexistence in nuclei can be fairly judged to have advanced in status from an exotic rarity twenty years ago to a widespread feature ${ }^{1)}$ of nuclear structure today. Possibly it occurs in all nuclei.

Unfortunately, it is not always easy to identify experimentally. In ideal circumstances it is clearly defined by, e.g., a rotational band with a small rotational constant and large intraband transition B(E2) values. More commonly, coexisting shapes are obscured by mixing. Mixing distorts the energy patterns of bands and results in decay patterns that conceal the characteristic cascade of E2 transitions expected for a deformed band.

However, mixing of configurations with different shapes can give rise to electric monopole (E0) transitions ${ }^{23)}$. There is accumulating evidence that E0 transitions widely occur in association with shape coexistence because of this mixing and constitute a signature for the occurrence of shape coexistence. This accumulating evidence is the focus of the present paper.

The association of EO transitions with shape coexistence is particularly extensive in the neutron-deficient $Z \sim 82$ region. Experimental results from this region are used to illustrate the present discussion.

\section{Shape Coexistence in the Neutron-Deficient $Z-82$ Region .}

Shape coexistence has been established systematically in both doubly-even ${ }^{1.5}$ and odd-mass ${ }^{4.5}$ nuclei in the neutron-deficient $\mathrm{Pt}, \mathrm{Au}, \mathrm{Hg}, \mathrm{Tl}$, and $\mathrm{Pb}$ isotopes.

The evidence for shape coexistence in the even- $\mathrm{Hg}$ isotopes is the most clearcut. The systematics of the shape coexisting bands in the even-Hg isotopes are depicted in Fig. 1. The evidence in the even-Pt isotopes is more subtle. The systematics of the shape coexisting bands in the even-Pt isotopes are depicted in Fig. 2. Figures 3a,b show how the ground-state band in ${ }^{184} \mathrm{Pt}$ is identifiable as a structure which is more strongly deformed than the ground-state bands in other $N=106$ isotones. However, this feature of ${ }^{184} \mathrm{Pt}$ is masked at low spin by mixing. The evidence in the even- $\mathrm{Pb}$ isotopes is more limited. The candidates for the $\mathrm{I}^{\pi}=0^{+}, 2^{+}$members of the deformed bands in ${ }^{192,194,196} \mathrm{~Pb}$ are shown in Fig. 4. Evidence for strongly-deformed bands has been reported recently 


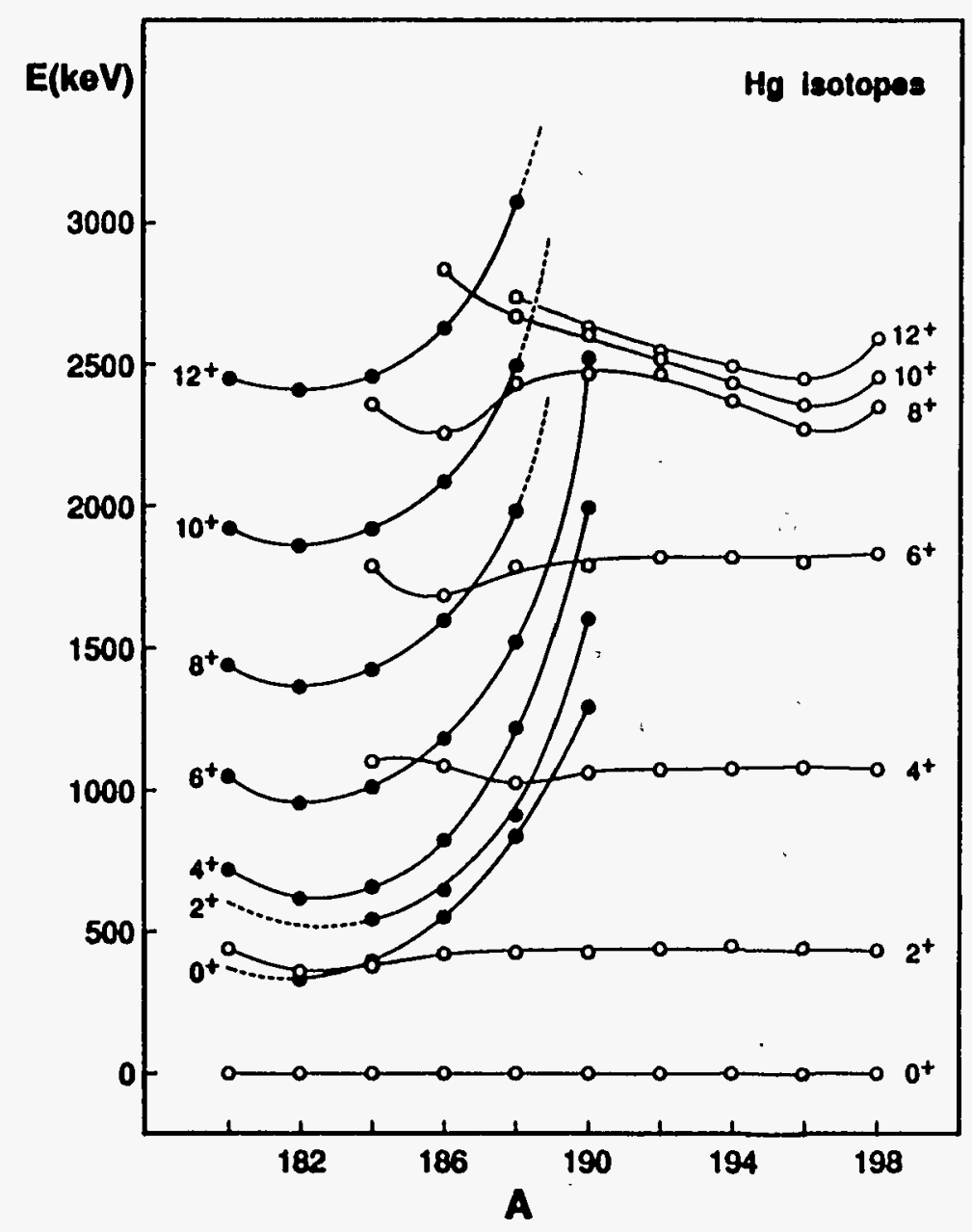

Fig. 1. The systematics of strongly-deformed bands (filled circles) and weakly-deformed bands (open circles) in even-mass $\mathrm{Hg}$ isotopes.

(The figure is adapted from ref.").

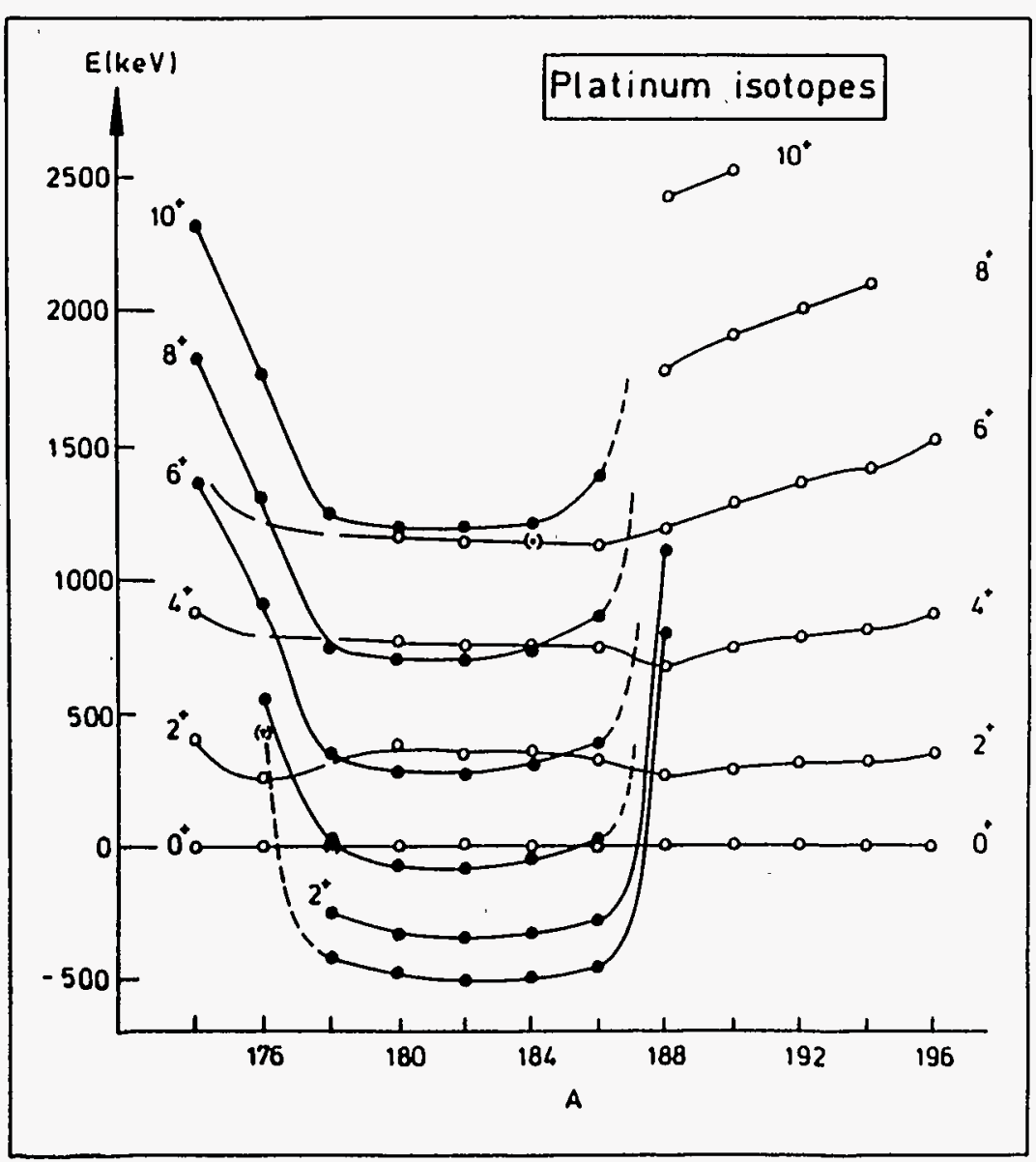

Fig. 2. The systematics of strongly-deformed bands (filled circles) and weakly-deformed bands (open circles) in even-mass $\mathrm{Pt}$ isotopes. (The figure is taken from ref."). 


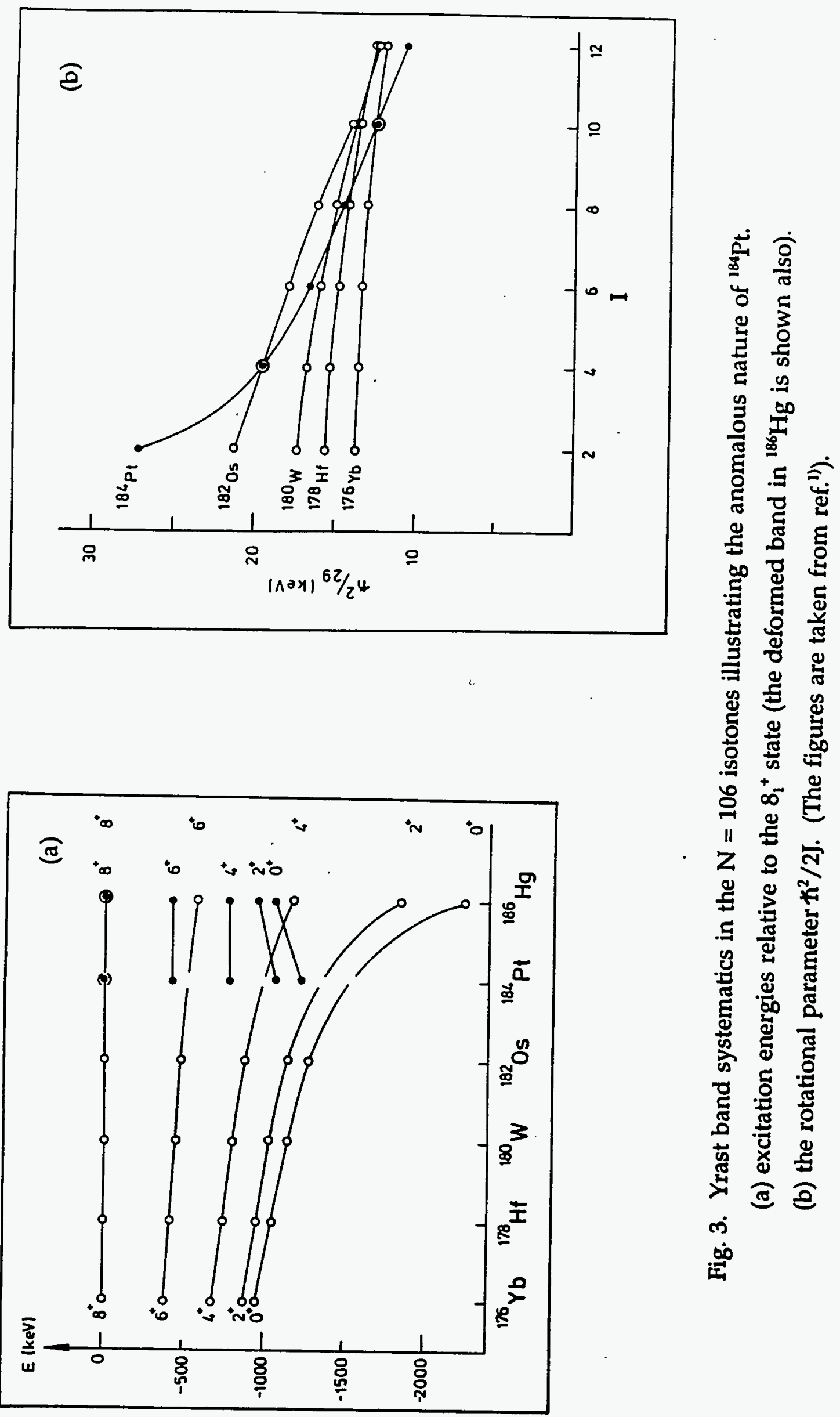


also for ${ }^{186,188} \mathrm{~Pb}$ (ref. $\left.{ }^{6}\right)$.

The evidence for shape coexistence in the $\mathrm{Au}$ and $\mathrm{Tl}$ isotopes is based on the observation of low-lying $h_{9 / 2}$ and $i_{13 / 2}$ intruder states. These states are expected to lie at high-excitation energy near closed shells where spherical nuclear shapes predominate. Their appearance at low excitation energy in the neutron-deficient $\mathrm{Au}\left(\right.$ refs. $^{4.57 .8)}$ ) and $\mathrm{Tl}$ (refs. ${ }^{4.59 .10)}$ ) isotopes is explained by invoking a larger deformation for these intruder states than for the $s_{1 / 2}, d_{3 / 2}, d_{5 / 2}$, and $h_{11 / 2}$ (non-intruder) states. The differences in deformation of the intruder states and non-intruder states is directly supported by lifetime data ${ }^{11)}$ for E2 transitions in the ${ }^{185-189} \mathrm{Au}$ isotopes.

There is direct evidence of shape coexistence in ${ }^{185} \mathrm{Hg}$ from optical hyperfine spectroscopy ${ }^{12)}$ which establishes an extremely large isomer shift for the mean-square charge radius of the ground state (which is deduced to be strongly deformed) and an $I^{\pi}=13 / 2^{+}$isomer (which is deduced to be weakly deformed). This result is a dramatic confirmation of the observation by Bonn et al. ${ }^{13)}$ of a sudden change in mean-square charge radii of the ground states of the neutron-deficient $\mathrm{Hg}$ isotopes between ${ }^{187} \mathrm{Hg}$ and ${ }^{185} \mathrm{Hg}$ and its interpretation ${ }^{13}$ as a sudden onset of deformation. (It was the work of Bonn et al. which first indicated the presence of low-lying shape coexistence in this region.)

\section{Electric Monopole Transitions in the Neutron-Deficient $Z-82$ Region}

Electric monopole transitions are a widespread feature of neutron-deficient $\mathrm{Pt}, \mathrm{Au}$, $\mathrm{Hg}$, and $\mathrm{Pb}$ isotopes (to date, no $\mathrm{E} 0$ transitions have been observed in the $\mathrm{Tl}$ isotopes). The most dramatic examples of E0 transitions are in ${ }^{184} \mathrm{Pt}$ and ${ }^{185} \mathrm{Pt}$. The low-lying band structure and associated $\mathrm{E} 0$ transitions observed ${ }^{14)}$ in ${ }^{184} \mathrm{Pt}$ are shown in Fig. 5. Examples of $\gamma$-ray-gated $\gamma$ spectra and $\gamma$-ray-gated conversion-electron spectra supporting the E0 transitions shown in Fig. 5 are presented in Figs. 6 a, b, and c. The low-lying levels associated with some of the E0 transitions observed ${ }^{15}$ in ${ }^{185} \mathrm{Pt}$ are shown in Fig. 7. Examples of $\gamma$-ray-gated conversion-electron spectra supporting some of the E0 transitions shown in Fig. 7 are presented in Fig. 8. It should be noted that six transitions in ${ }^{185} \mathrm{Pt}$ have no observable ${ }^{19} \gamma$-decay strength (five of these six transitions are shown in Figs. 8a-d); further the $530 \mathrm{keV}$ transition between the $3^{+}$states at 940 and $1470 \mathrm{keV}$ in 


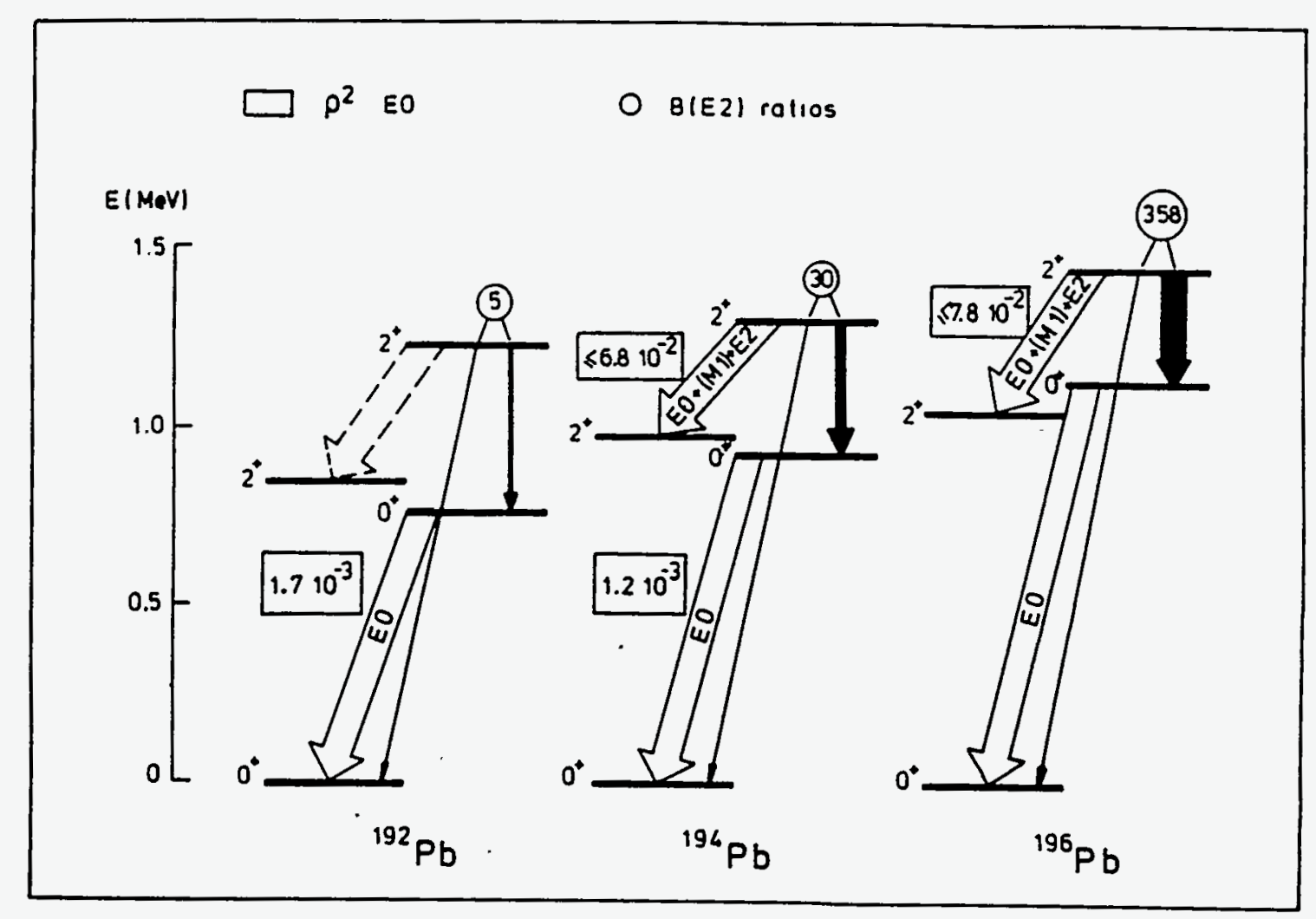

Fig. 4. Electromagnetic decay data for low-spin candidates of the deformed bands in ${ }^{192-196} \mathrm{~Pb}$. (The figure is taken from ref. ${ }^{1)}$ ).

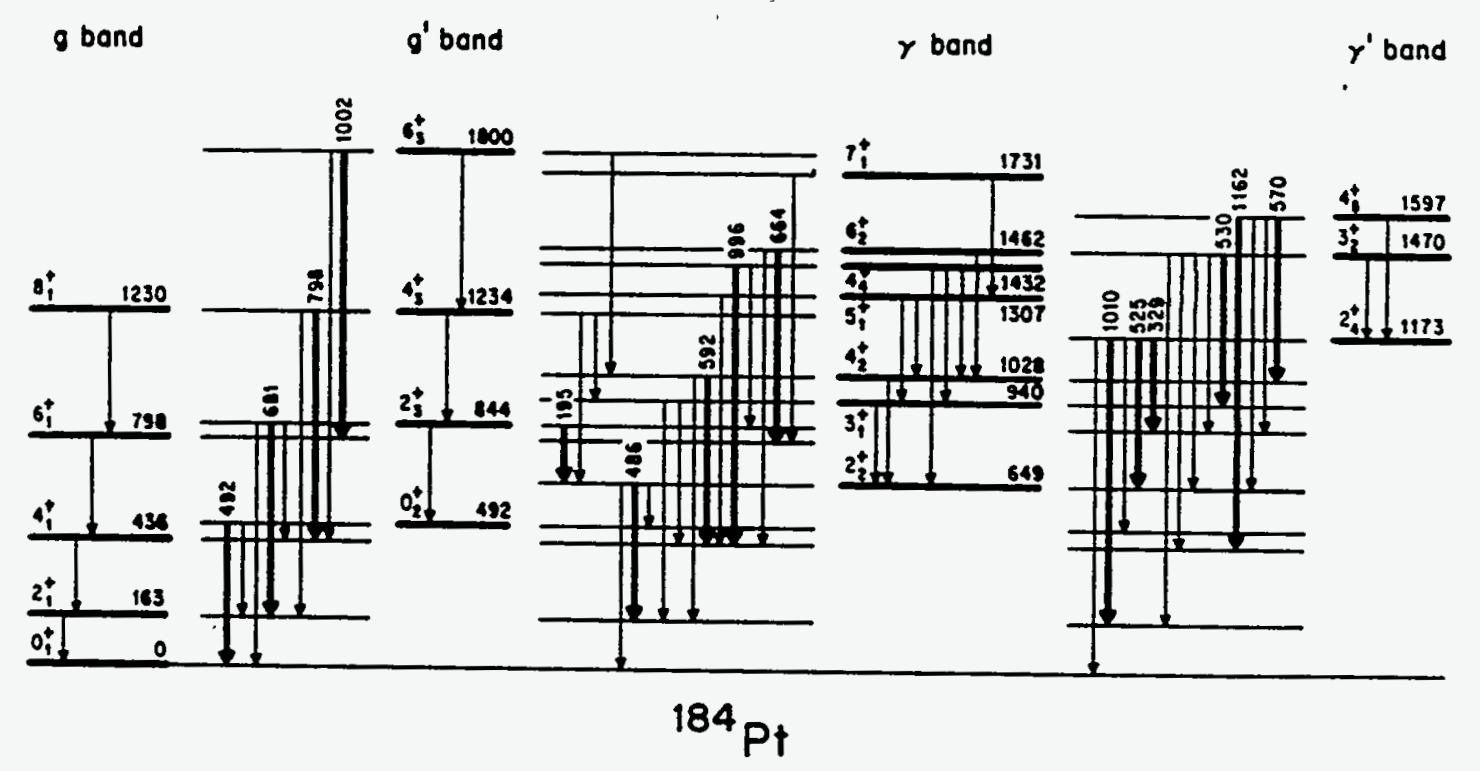

Fig. 5. The low-lying band structure and associated E0 transitions in ${ }^{184} \mathrm{Pt}$. (The figure is taken from ref. ${ }^{14)}$ ). 

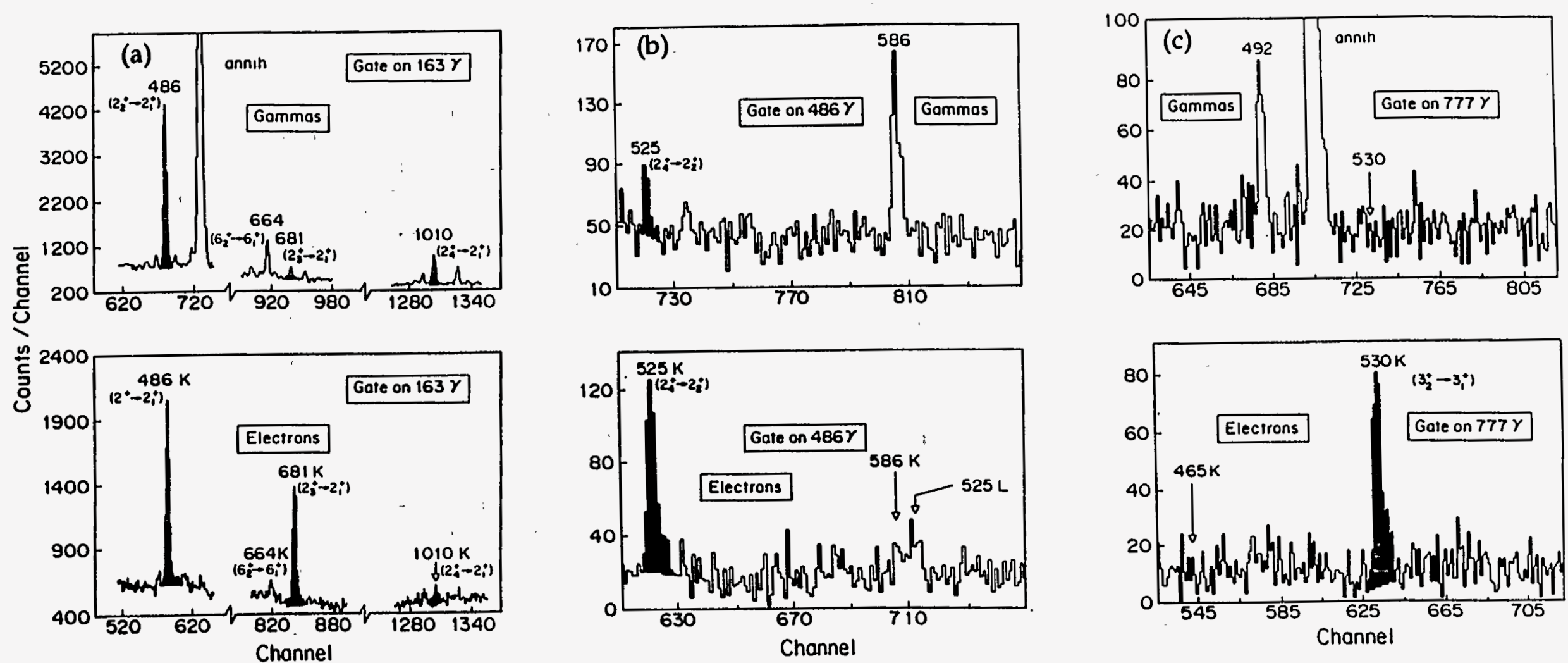

Fig. 6. Gamma-ray-gated $\gamma$ spectra and conversion-electron spectra supporting E0 transitions in ${ }^{184} \mathrm{Pt}$ between: (a) the $2_{3}{ }^{+}$and $2_{1}{ }^{+}$states; (b) the $2_{1}{ }^{+}$and $2_{2}{ }^{+}$states; and (c) the $3_{2}{ }^{+}$and $3_{1}{ }^{+}$states. The $3_{2}^{+} \rightarrow 3_{1}^{+}$transition is pure E0 within the statistics of the data. (The figures are taken from ref. ${ }^{14)}$ ). 


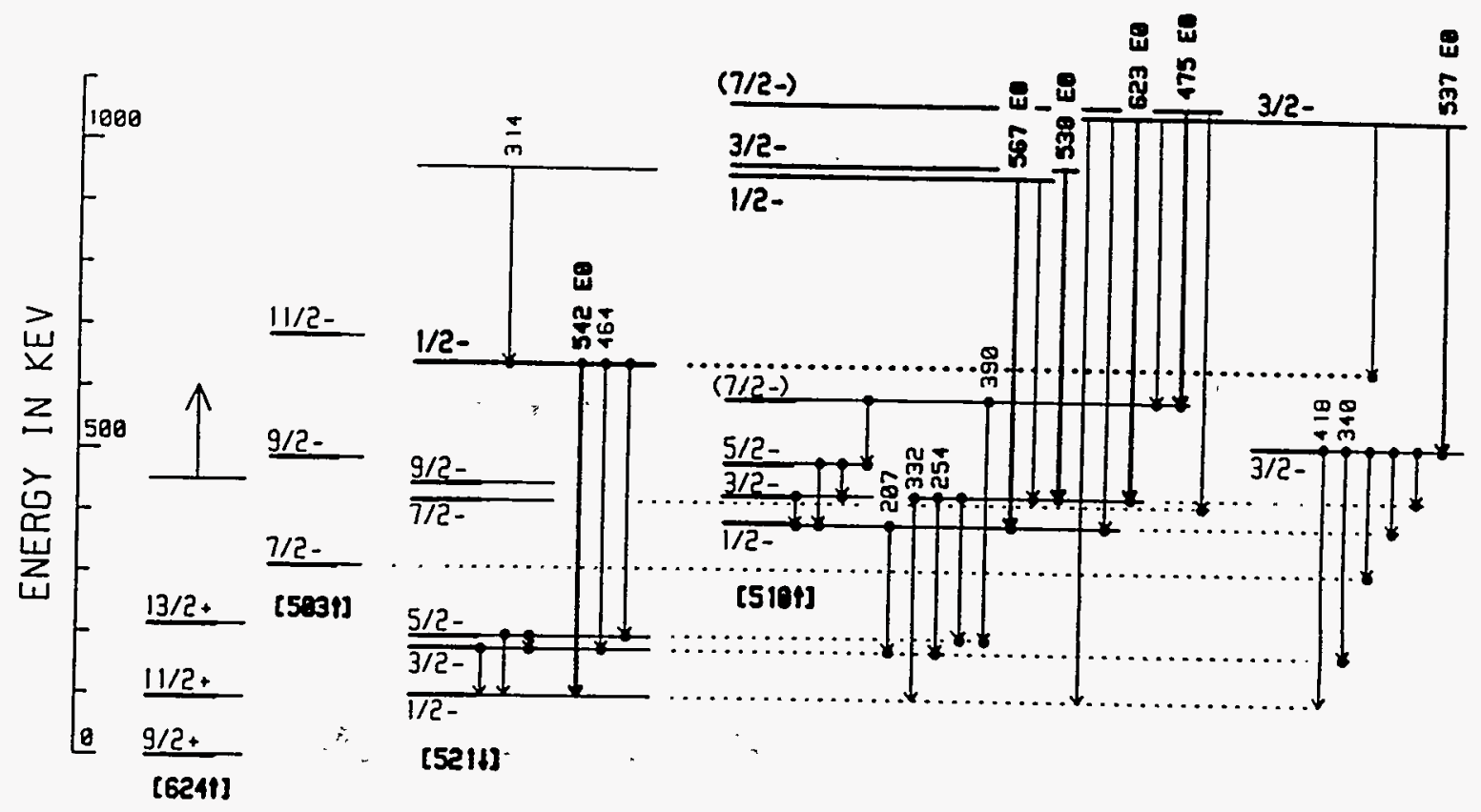

Fig. 7. The low-lying levels and pure E0 transitions in ${ }^{185} \mathrm{Pt}$. (The figure is taken from ref. $\left.{ }^{15}\right)$. 

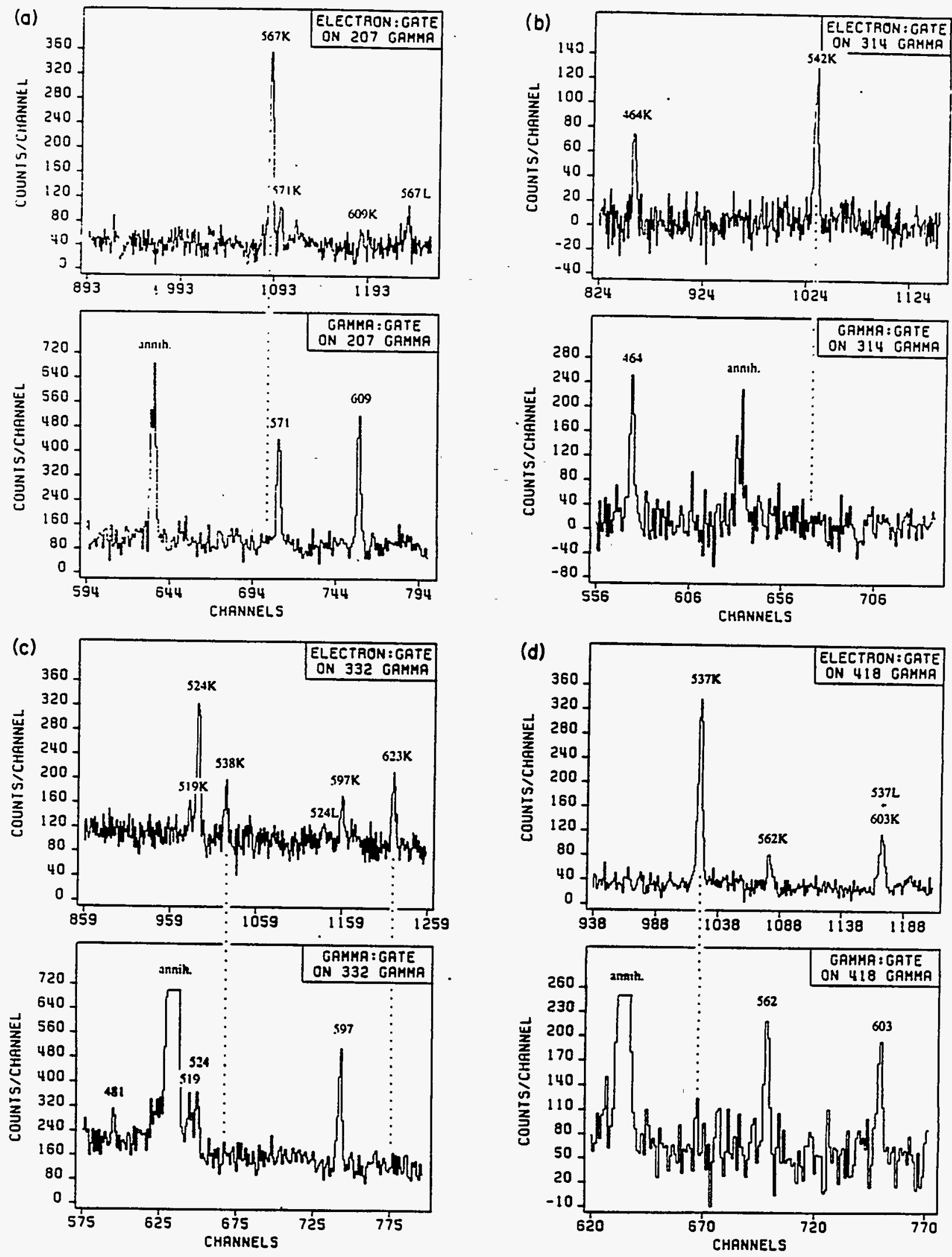

Fig. 8. Gamma-ray gated $\gamma$ spectra and conversion-electron spectra supporting pure E0 transitions in ${ }^{185} \mathrm{Pt}$. (The figure is taken from ref. ${ }^{15}$ ). 

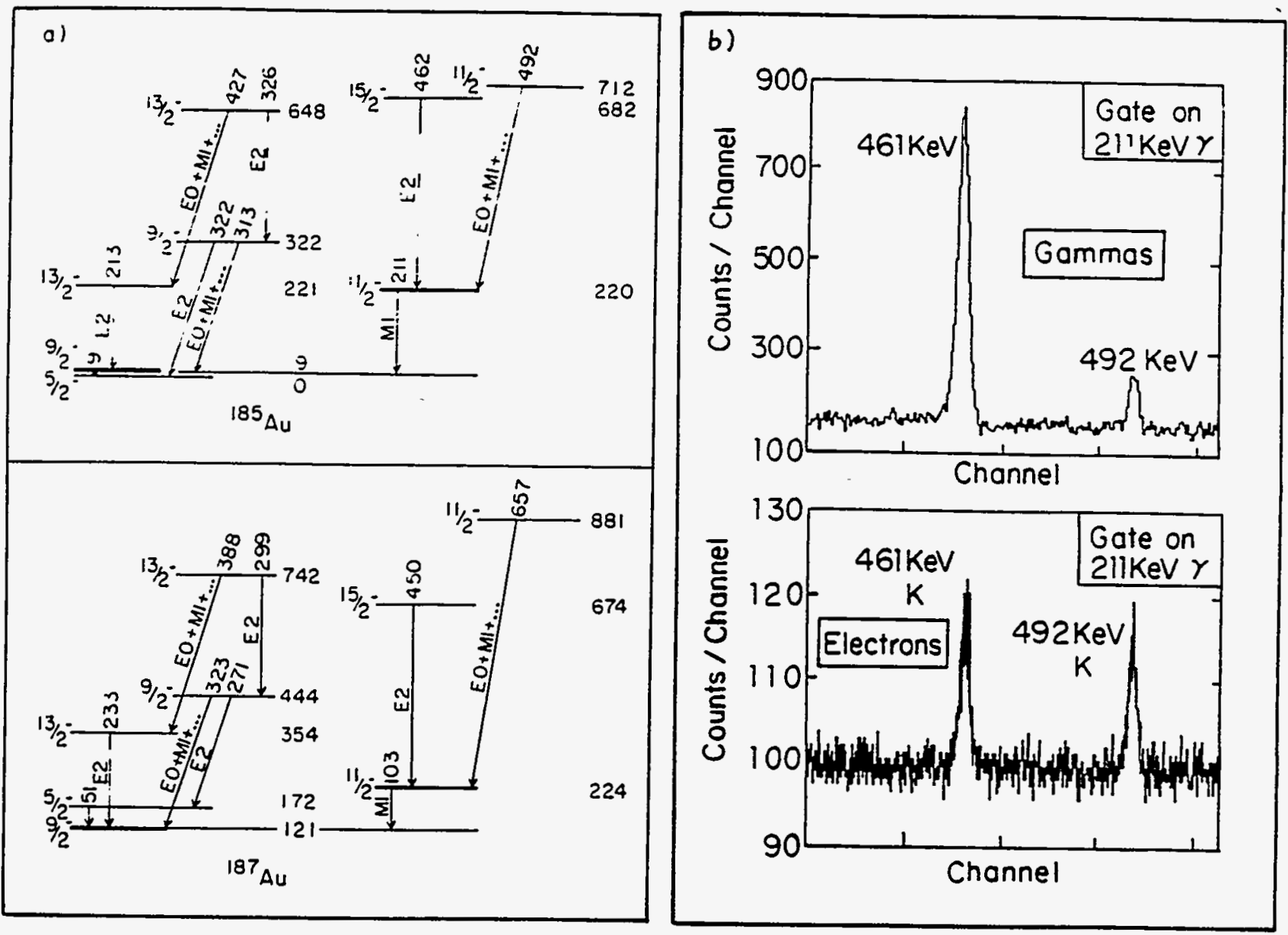

Fig. 9. (a) The band structures in ${ }^{185,187} \mathrm{Au}$ associated with E0 transitions. (b) Gamma-ray gated $\gamma$ spectrum and conversion-electron spectrum supporting an $11 / 2^{-} \rightarrow 11 / 2^{-}$ E0 transition in ${ }^{185} \mathrm{Au}$. (The figures are taken from ref. ${ }^{17}$ ).
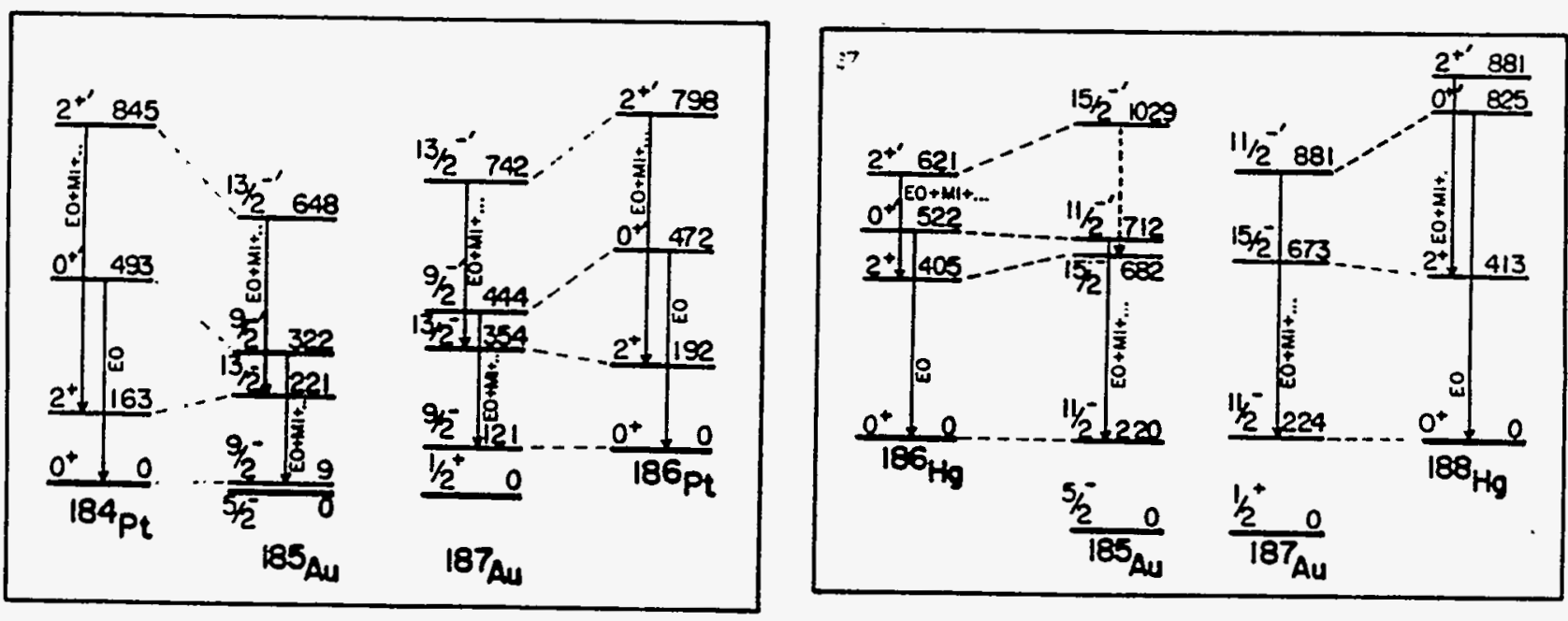

Fig. 10. The connection between the E0 transitions in ${ }^{185,187} \mathrm{Au}$ and the E0 transitions in the neighboring even mass $\mathrm{Pt}$ and $\mathrm{Hg}$ isotopes for: (a) the $\mathrm{h}_{9 / 2}$ particle states; (b) the $h_{11 / 2}$ hole states. (The figures are taken from ref. ${ }^{17}$ ). 
${ }^{184} \mathrm{Pt}$ has no observable $\gamma$-decay strength (see Fig. 6c). (An essentially identical pattern of E0 transitions to that seen ${ }^{14)}$ in ${ }^{184} \mathrm{Pt}$ is evident ${ }^{16)}$ also in ${ }^{186} \mathrm{Pt}$.)

In ${ }^{185,187} \mathrm{Au}$ a systematic pattern of E0 transitions is observed ${ }^{17,18)}$ in association with the $h_{11 / 2}$ states and the $h_{9 / 2}$ intruder states. This is depicted in Figs. 9a. The connection between the states in ${ }^{185,187} \mathrm{Au}$ shown in Figs. 9a and coexisting states in ${ }^{184.186} \mathrm{Pt}$ and ${ }^{186.188} \mathrm{Hg}$ is shown in Figs. 10a,b. The implication of Figs. 10a,b is that in ${ }^{185,187} \mathrm{Au}$ there are four different coexisting structures: two associated with the $h_{11 / 2}$ proton hole structure and two associated with the $h_{9 / 2}$ proton particle (intruder) structure.

Summaries of E0 transitions in association with shape coexistence in the $Z \sim 82$ region and other regions can be found in refs. ${ }^{19,20)}$.

\section{The Origin of EO Transition Strength}

The E0 strength parameter, $p$, is defined by

$$
\rho_{y}=\left\langle f\left|\sum \rho_{j}^{2}\right| i>\right| e R^{2},
$$

where the sum is over nucleons, $e_{j}$ is the effective monopole charge of the $j$ th nucleon, $e$ is the unit of electric charge, and $R^{2}=\left(1.2 A^{1 / 3} \mathrm{fm}\right)^{2}$ is the mean-square nuclear radius. Rates of E0 transitions are given by

$$
\frac{1}{\tau(E O)}=\rho_{t}^{2} \Sigma_{k} \Omega_{k}(Z, E)
$$

where $\tau(E 0)$ is the lifetime for E0 decay and $\Omega_{k}(Z, E)$ is the electronic factor which depends on the nuclear charge, $Z$, and the transition energy, $E$, and $k$ labels the various processes by which the E0 transition occurs: $K_{-}, L_{1}^{-}, L_{2}^{-}, \ldots, M_{1}^{-}, \ldots$ shell internal conversion and internal pair formation.

The strength of EO transitions is greatest when the states $|i\rangle$ and $|f\rangle$ are linear combinations of two configurations, $|1\rangle$ and $|2\rangle$, such that the mean-square radii of $|1\rangle$ and $|2\rangle$ are very different. Thus (defining $\Sigma_{1} e_{i j}{ }_{i}^{2} \equiv m(E 0),<f|m(E 0)| i>\equiv M_{i f}(E 0)$ ), 


$$
|i>=\alpha| 1>+\beta|2>,| \beta=-\beta|1>+\alpha| 2>,
$$

and

$$
M_{6}(E O)=\alpha \beta<2|m(E O)| 2>-<1|m(E O)| 1>+\alpha^{2}<2|m(E O)| 1>-\beta^{2}<1|m(E O)| 2>
$$

This reduces, in practice, to

$$
M_{0}(E O)=\alpha \beta \Delta<r^{2}>,
$$

i.e., $\mathrm{M}_{\mathrm{in}}(\mathrm{E} 0)$ is proportional to the mixing of the configurations ( $\alpha$ and $\beta$ ) and the difference in their mean-square radii. This is a completely general result and is not dependent on any specific nuclear model. Evidently, $\mathrm{M}_{\mathrm{if}}(\mathrm{E} 0)$ will be large whenever the initial and final states involve mixed configurations with very different mean-square radii such as would occur when shape coexistence is present. Caution is needed, however, because configurations with very different mean-square radii can occur with near-degenerate energies as a result of the spin-orbit depression of high-j orbits and as a result of deformed mean-field effects.

A single-particle unit of strength for $\rho^{2}$ of $0.5 \mathrm{~A}^{-2 / 3}$ has been given by Bohr and Mottelson ${ }^{21}$.

\section{A Brief Survey of E0 Strength}

The E0 strength of transitions is conventionally quoted as $\rho^{2} \times 10^{3}$. Of greatest interest are answers to the questions: What are the strongest and weakest $\mathrm{E} 0$ transitions and where do they occur?

The weakest E0 known is from the decay of the "fission" isomer in ${ }^{238} \mathrm{U}$. This is shown in Fig. 11. The next weakest E0 transition known is in ${ }^{58} \mathrm{Ni}$. This is dramatized by the fact that ${ }^{50} \mathrm{Ni}$ also possesses a strong E0 transition. These details for ${ }^{58} \mathrm{Ni}$ are shown in Fig. 12. The behavior of ${ }^{238} \mathrm{U}$ reveals that shape coexistence alone does not generate E0 strength (mixing also is necessary). The behavior of ${ }^{58} \mathrm{Ni}$ contrasts a mixing of neutron configurations from the same shell (similar mean-square radii) and a mixing of proton ${ }^{-1}$ configurations from different shells: the $0^{+}$state at $3531 \mathrm{keV}$ in ${ }^{58} \mathrm{Ni}$ involves a proton pair excitation across the $Z=28$ shell. The weakness of the E0 transition 


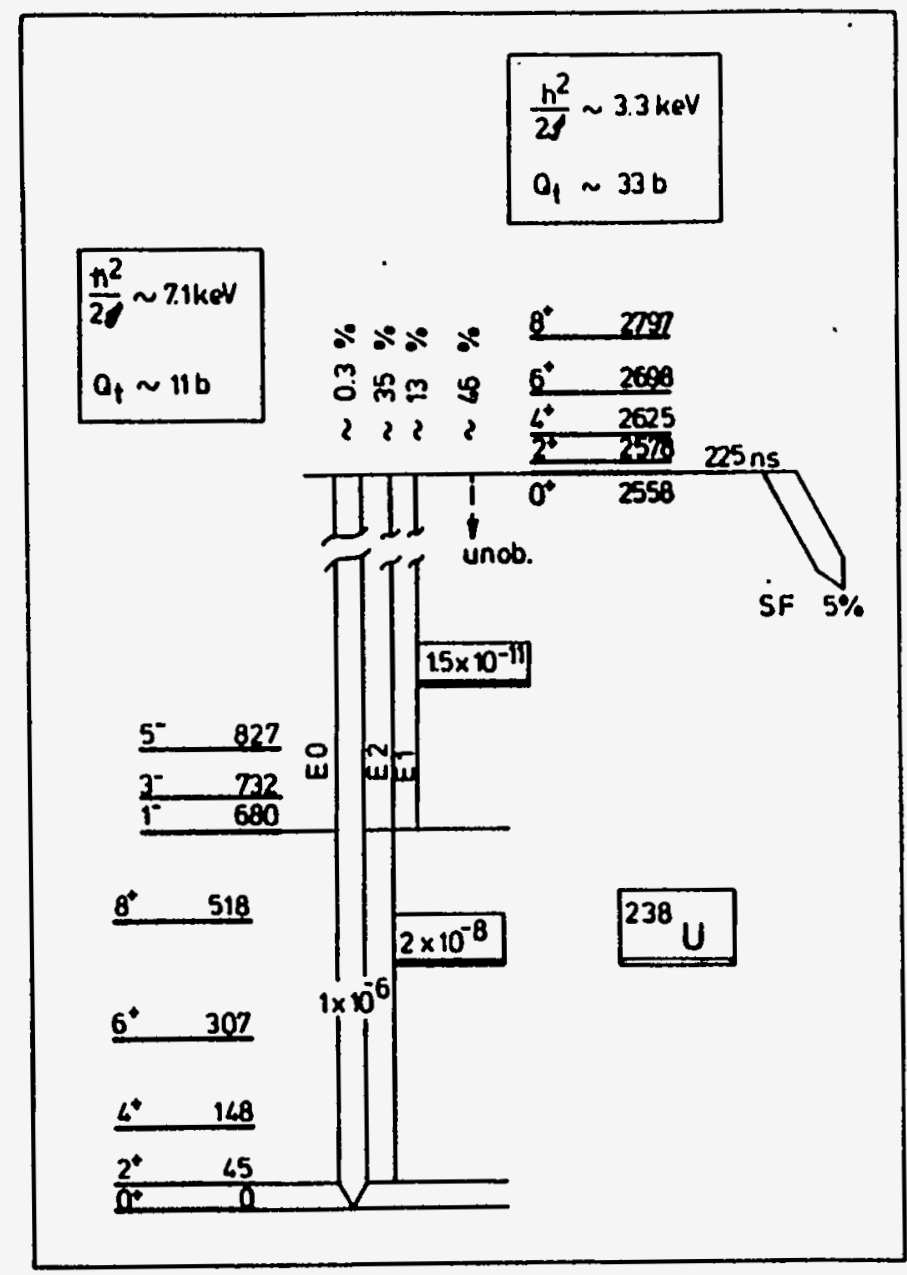

Fig. 11. Electromagnetic decay data for the fission isomer in ${ }^{238} \mathrm{U}$. (The figure is taken from ref. $\left.{ }^{1}\right)$.

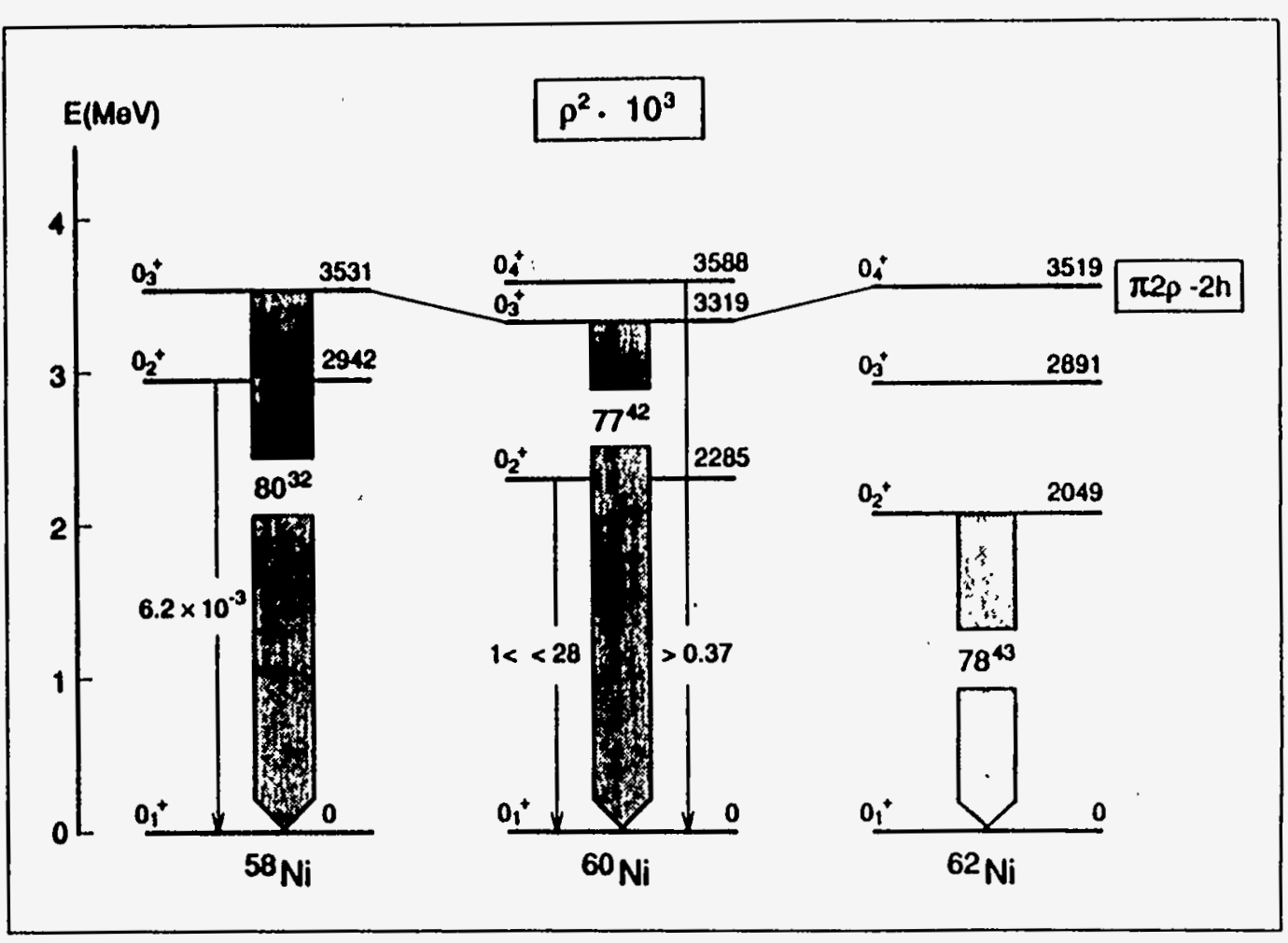

Fig. 12. Electric monopole transitions in ${ }^{58,60,62} \mathrm{Ni}$. The E0 transition between the $\mathrm{O}_{2}{ }^{+}$and $\mathrm{O}_{1}{ }^{+}$states in ${ }^{58} \mathrm{Ni}$ is second in slowness only to the $\mathrm{EO}$ decay of the fission isomer in ${ }^{238} \mathrm{U}$. The $\mathrm{E} 0$ transition between the $0_{3}{ }^{+}$and $0_{1}{ }^{+}$states in ${ }^{58} \mathrm{Ni}$ is one of the fastest known. The E0 data are from ref. ${ }^{22}$ and the proton-pair excitation ( $(12 \mathrm{p}-2 \mathrm{~h})$ identifications are from ref. ${ }^{23)}$. 


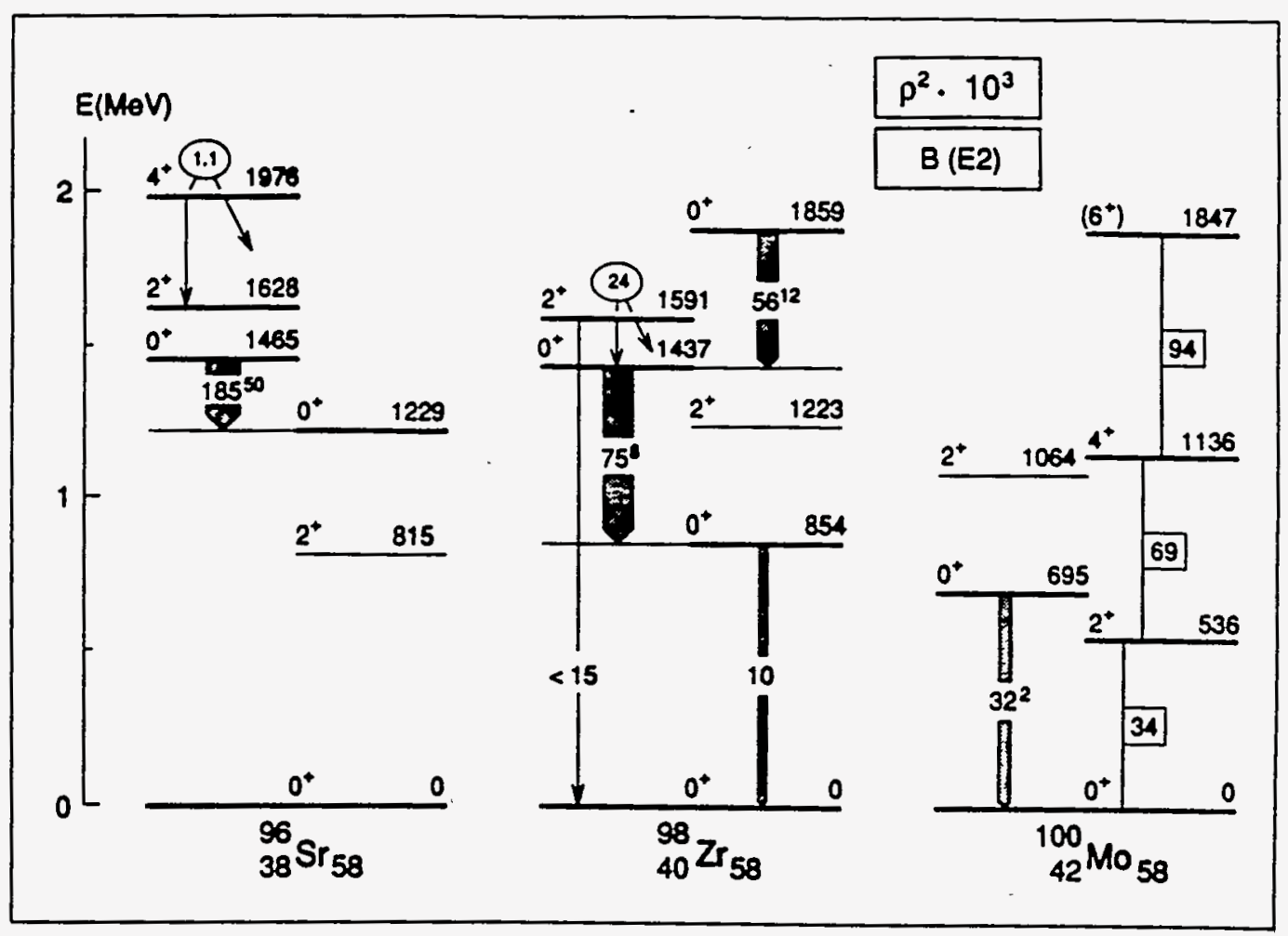

Fig. 13. Electromagnetic decay data for $\mathrm{N}=58$ isotones. The $\mathrm{EO}$ transition between the $\mathrm{O}_{3}{ }^{+}$and $\mathrm{O}_{2}^{+}$states in ${ }^{96} \mathrm{Sr}$ is the fastest known for $\mathrm{A}>56$. The numbers in circles are in-band/out-of-band $B(E 2)$ ratios. The data are taken from refs..$^{25.2627}$ and Nuclear Data Sheets.

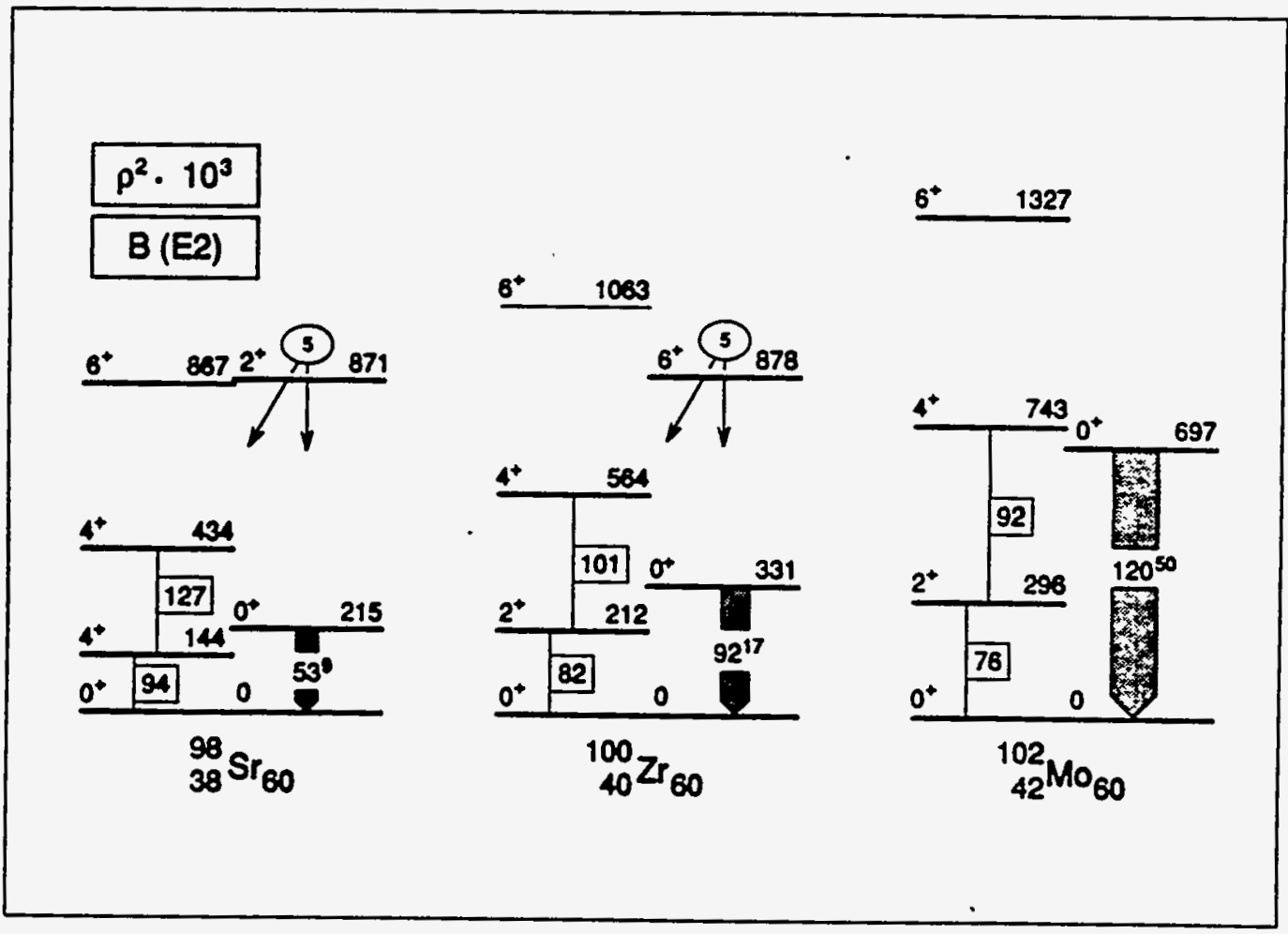

Fig. 14. Electromagnetic decay data for $\mathrm{N}=60$ isotones, cf. Fig. 13. The figure is adapted from ref. ${ }^{1)}$ with additional data from ref. ${ }^{26)}$ and Nuclear Data Sheets. 


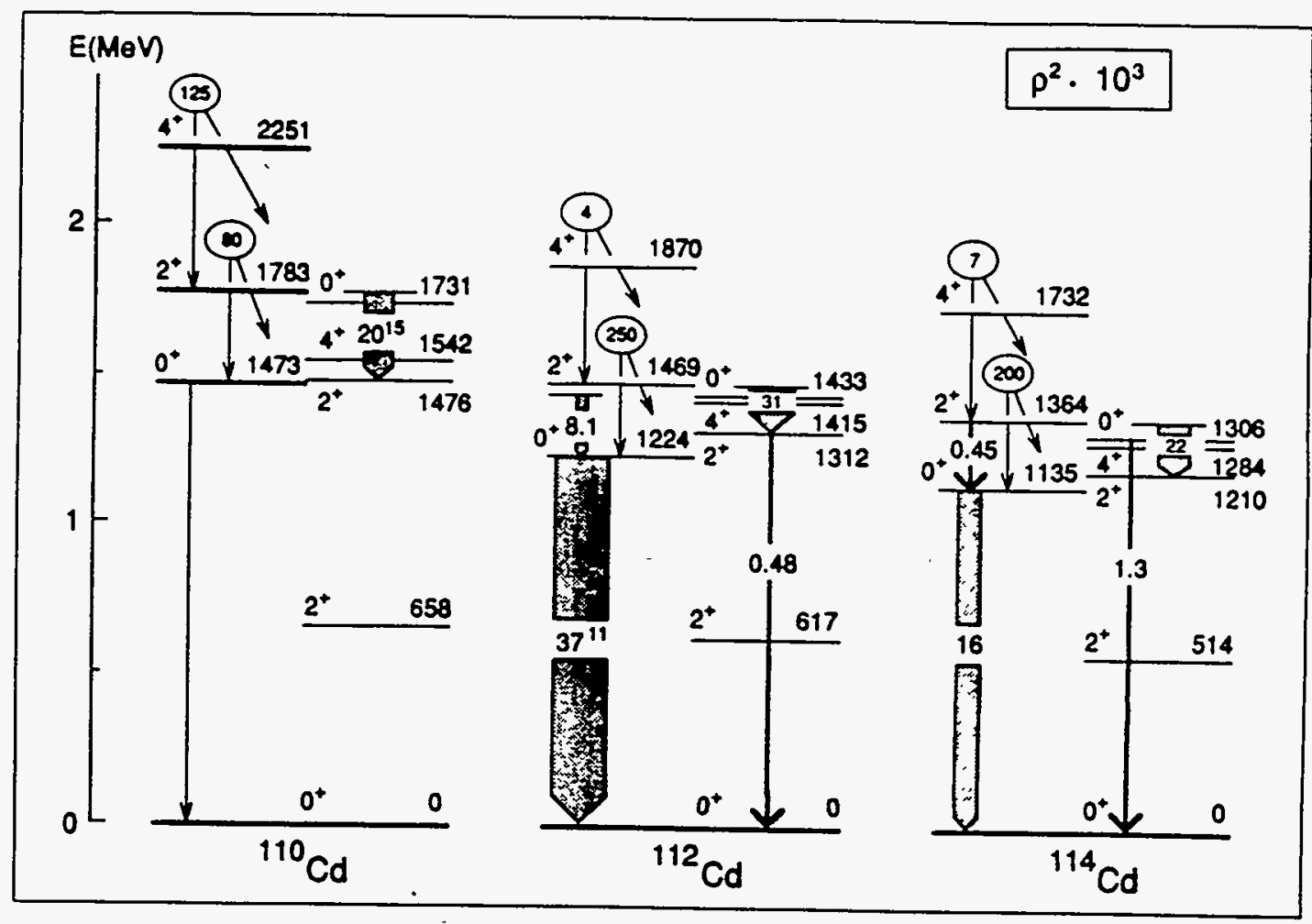

Fig. 15. Electromagnetic decay data for ${ }^{110,112,114} \mathrm{Cd}$, cf. Fig. 13. The data are taken from refs. ${ }^{12829)}$ and Nuclear Data Sheets. (See also Fig. 3.1.7 in ref. ${ }^{1}$ ).

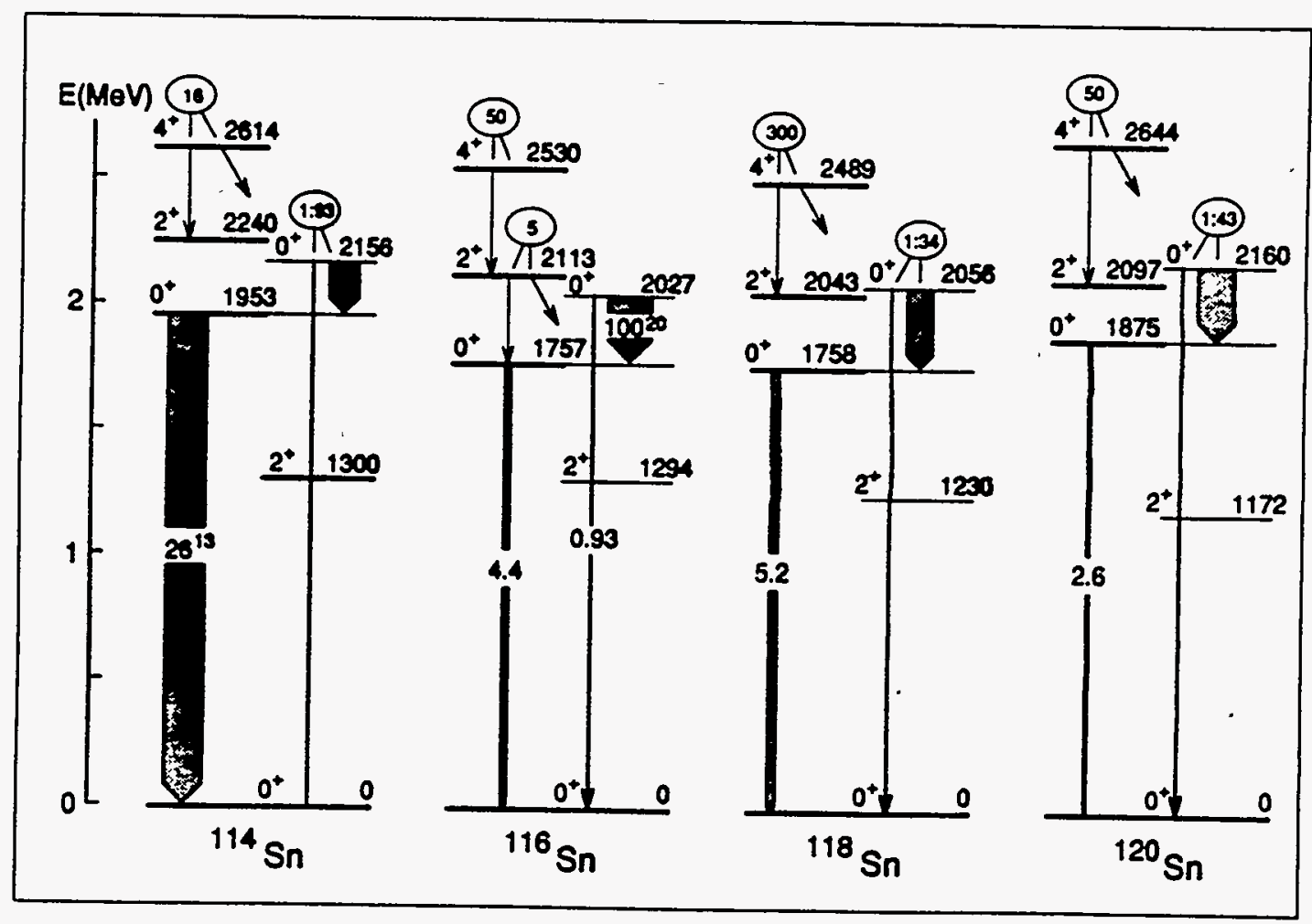

Fig. 16. Electromagnetic decay data for ${ }^{11+120} \mathrm{Sn}$, cf. Fig. 13. The data are taken from refs. ${ }^{130)}$ and Nuclear Data Sheets. 


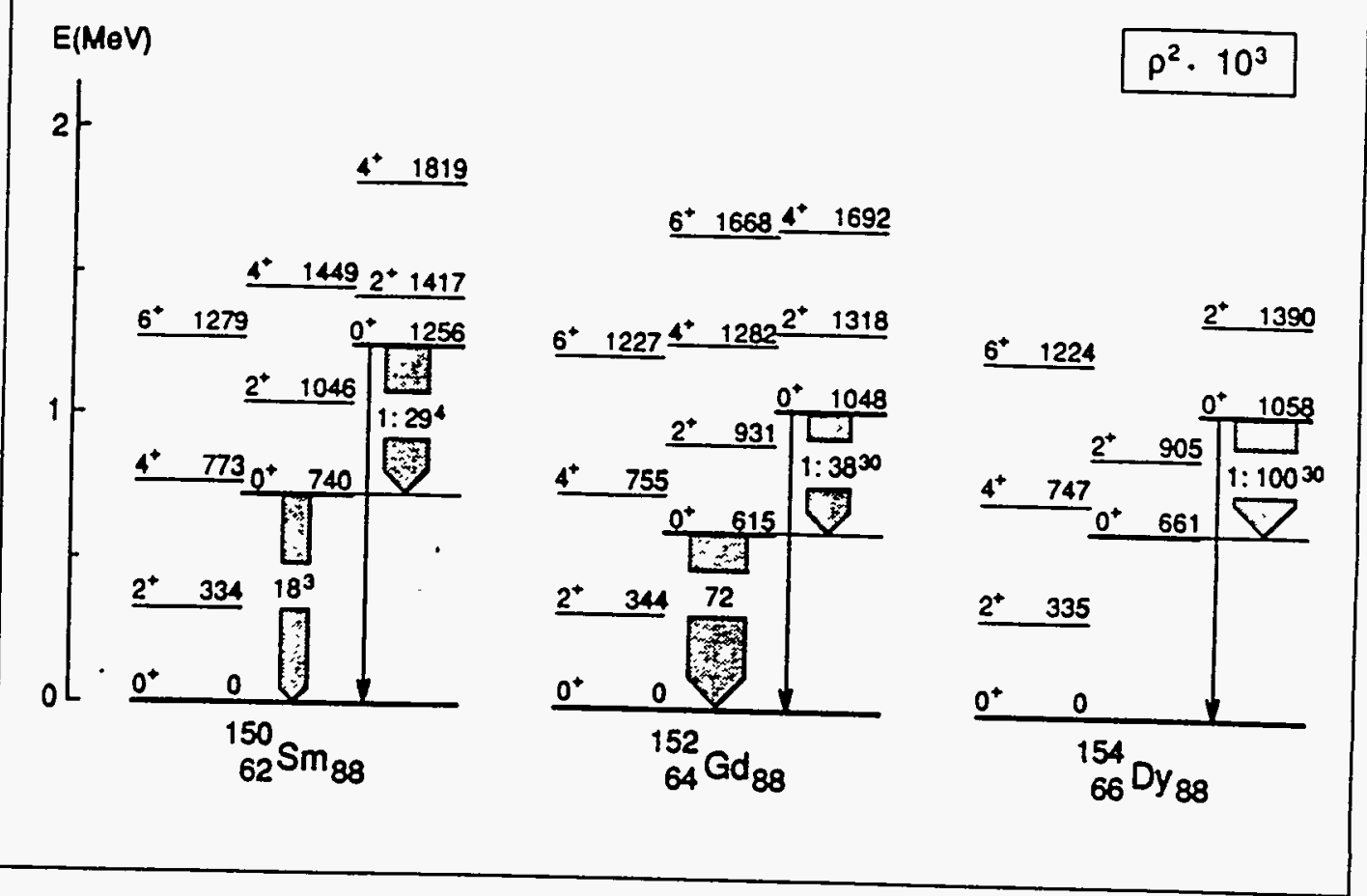

Fig. 17. Electromagnetic decay data for $\mathrm{N}=88$ isotones, cf. Fig. 13. The data are taken from ref. ${ }^{31)}$ and Nuclear Data Sheets.

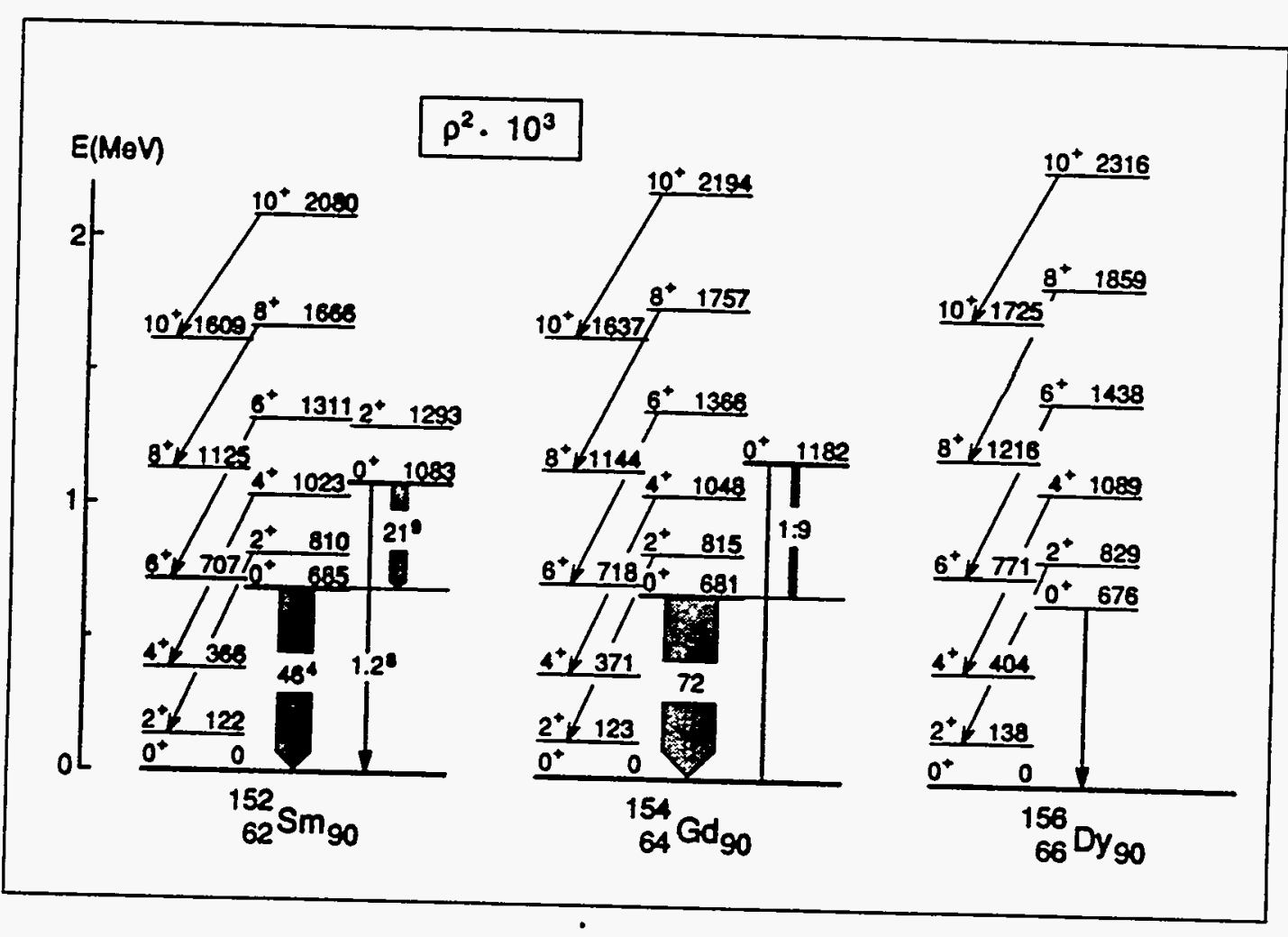

Fig. 18. Electromagnetic decay data for $\mathrm{N}=90$ isotones, cf. Fig. 13. The data are taken from ref. ${ }^{32)}$ and Nuclear Data Sheets. 
involving the neutron configurations is in part due to the very small neutron monopole effective charge. This translates into a very small core polarizability in ${ }^{58} \mathrm{Ni}$. core polarizability increases with mass. Thus, the $\rho^{2}\left(0_{2}{ }^{+} \rightarrow 0_{1}^{+}\right)$observed ${ }^{24)}$ in ${ }^{k} 86 \mathrm{~Pb}$ is 150 times larger than $\rho^{2}\left(\mathrm{O}_{2}{ }^{+} \rightarrow \mathrm{O}_{1}{ }^{+}\right)$in ${ }^{58} \mathrm{Ni}$.

The strongest E0 transitions are observed between $0^{+}$states in the lightest nuclei. Typical $\rho^{2} \times 10^{3}$ values ${ }^{25}$ are in the range $150-500$. In part, these large values reflect the presence of multiparticle-multihole configurations at low energy in light nuclei (see, e.g.,

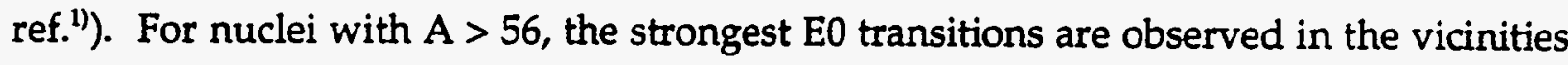
of: ${ }^{98,100} \mathrm{Zr}$ (cf. Figs. 13,14), ${ }^{114} \mathrm{Cd},{ }^{116} \mathrm{Sn}$ (cf. Figs. 15,16), and ${ }^{152,154} \mathrm{Gd}$ (cf. Figs. 17,18). These nuclei all lie in regions of well-established shape coexistence ${ }^{1)}$.

Unfortunately, lifetime data (of $\mathrm{O}_{2}^{+}$states) in the vicinity of ${ }^{184} \mathrm{Pt}$ are very limited. There are very recent measurements ${ }^{33)}$ for ${ }^{186,188} \mathrm{Hg}$. These indicate little mixing in ${ }^{188} \mathrm{Hg}$ and (at least) moderate mixing in ${ }^{186} \mathrm{Hg}$, with $\rho^{2} \times 10^{3}$ values of 7.7 and $\geq 32$, respectively, for the $\mathrm{O}_{2}^{+} \rightarrow \mathrm{O}_{1}^{+}$transitions.

Of particular interest are a number of regions where $\rho^{2}\left(\mathrm{O}_{3}{ }^{+} \rightarrow \mathrm{O}_{2}^{+}\right) \gg \rho^{2}\left(\mathrm{O}_{3}{ }^{+} \rightarrow \mathrm{O}_{1}{ }^{+}\right.$) (cf. Figs. 13,15-18) suggesting that $\mathrm{O}_{2}^{+}$and $\mathrm{O}_{3}{ }^{+}$states are mixed configurations with very different mean-square charge radii. All of these regions exhibit shape coexistence.

There is a serious lack of information on $\rho^{2}$ values in deformed nuclei. A major effort is needed to systematize $\rho^{2}$ values in deformed nuclei.

This work is based on an extensive collaboration with E. F. Zganjar (Louisiana State University) and $\mathrm{K}$. Heyde (Rijksuniversiteit, Gent). Support of the present work has been in part by U. S. Department of Energy Grant DE-FG05-87ER 40330 and in part by NATO Grant RG-92/0011/R.

\section{References}

1) J. L. Wood et al., Phys. Repts. 215 (1992) 101

2) J. Kantele, in Heavy Ions and Nuclear Structure, Proceedings of the XIV Summer School, Mikolajki, Poland, 1984, eds. B. Sikora and Z. Wilhelmi (Harwood Academic, New York, 1984), p. 391

3) K. Heyde and R. A. Meyer, Phys. Rev. C37 (1988) 2170

4) K. Heyde et al., Phys. Repts. 102 (1983) 291 
5) J. H. Hamilton et al., Rep. Prog. Phys. $\underline{48}$ (1985) 631

6) J. Heese et al., Phys. Lett. B302 (1993) 390; A. M. Baxter et al., Phys. Rev. C48 (1993) R2140

7) M. Kortelahti et al., J. Phys. G14 (1988) 1361

8) V. P. Janzen et al., Phys. Rev. C45 (1992) 613

9) P. Van Duppen et al., Nucl. Phys. A529 (1991) 268

10) W. Reviol et al., Phys. Rev. C49 (1994) R587; G. J. Lane et al., Phys. Lett. B324 (1994) 14

11) V. Berg et al., Nucl. Phys. A410 (1983) 445; ibid. A244 (1975) 462

12) G. Ulm et al., Z. Phys. A325 (1987) 247

13) J. Bonn et al., Phys. Lett. B38 (1972) 308

14) Y.-S. Xu et al., Phys. Rev. Lett. 68 (1992) 3853

15) J. Schwarzenberg et al., Phys. Rev. C45 (1992) R896

16) J. McEver et al., Bull. Am. Phys. Soc. 38 (1993) 1819

17) C. D. Papanicolopulos et al., Z. Phys. A.330 (1988) 371

18) D. Rupnik, Ph.D. thesis, Louisiana State University, 1994

19) E. F. Zganjar and J. L. Wood, in Proc. Int. Workshop on Nuclear Structure in the Zirconium Region, Bad Honef, Germany, april 24-28, 1988, ed. J. Eberth et al., (Springer Verlag, Berlin, 1988), p. 88

20) E. F. Zganjar and J. L. Wood, Nucl. Phys. A520 (1990) 427c

21) A. Bohr and B. R. Mottelson, Nuclear Structure, Vol. 2 (Benjamin, Reading, Massachusetts, 1975), pp. 174, 358, and 552

22) A. Passoja et al., Nucl. Phys. A363 (1981) 399

23) W. P. Alford et al., Nucl. Phys. A243 (1975) 269; N. Stein et al., Phys. Rev. Lett. 38 (1977) 587

24) R. Julin et al., Phys. Lett. B65 (1976) 337

25) N. A. Voinova-Eliseeva and I. A. Mitropolski, Sov. J. Part. Nucl. 17 (1986) 521

[Fiz. Elem. Chastits At. Yadra 17 (1986) 1173]

26) H. Mach et al., Phys. Rev. C41 (1990) 350

27) G. Lhersonneau et al., Phys. Rev. C49 (1994) 1379

28) A. Giannatiempo et al., Phys. Rev. C44 (1991) 1844 
29) R. Julin et al., Z. Phys. A296 (1980) 315

30) A. Backlin et al., Nucl. Phys. A351 (1981) 490

31) A. Passoja et al., J. Phys. G12 (1986) 1047

32) H. Mach et al., Phys. Rev. C46 (1992) 1849

33) P. K. Joshi et al., Int. J. Mod. Phys. E3 (1994) in press 